\title{
A Survey of Fire Modelling in France
}

\section{MICHEL R. CURTAT}

Centre Scientifique et Technique du Bâtiment

Boite Postale 02

77421 Marne La Vallée Cedex 2, France

ABSTRACT

A survey is made of what is being done in Erance on fire modelling. The author emphasizes the activities carried on the development and application of zone models and field models, started at the end of the $1970 \mathrm{~s}$ and concerning buildings or industrial fires. A list of laboratories and research centers is presented including also the places where full size expeeriments can be executed. The present trends towards applications to regulation and environment problems are shown.

KEY WORDS : Fire Modelling, Fire Research in France, Zone Models, Field Models, Fire simulation.

During the last few years, several articles and papers have provided excellent information on the mathematical modelling of fire its theoretical foundation, experiments in the field, the state of the art and the latest developments. The existence of these publications will allow me to assume that any basic scientific questions which I have only mentioned briefly or in passing have already been explored; I can thus devote the time and space available to me to the specific subject at hand.

When preparing this paper, I thought of dealing with questions such as "What is the situation of fire modeling today? What are the present possibilities of applying it to concrete safety problems ? How can the use of computer codes be included in fire regulations?" However, I decided that it would be of interest to describe what is happening in France. A good reason for choosing this subject is that we have not written very many reports on our fire modelling research activities in France; in fact, I am not aware of any that have been published in English! I must admit that much of the work carried out in France has not been the subject of reports in English and is therefore not known to the international scientific commity. I 
believe there are several reasons for "holding back" such information - speaking a foreign language is not always the favourite pastime of many of us; there are very few French fire safety researchers and they are sometimes more obliged to "work or publish" than to "publish or perish"; lastiy, some of the work is confidential. It is therefore an excellent opportunity for us to be able to speak of our work in the open, amicable framework of the IAFSS. However, our aim is not one of self-satisfaction or ego-boosting. Our choices, our organization, our ambitions, and what we have achieved can be criticized and such criticism can be constructive. I would like to take advantage of this opportunity to pay homage to the foreign researchers in our field whose work has been a source of information which we have not hesitated to use, as well as a source of encouragement, stimulation and often cordial exchange.

I have had to drastically prune the information I have received on work in which several laboratories have participated, some of them for the last fifteen years. I would therefore like to ask the indulgence of my French colleagues who have so kindly provided me with documents on their activities. In order to give a comprehensible overview in just a few pages without accumulating too many bibliographical references (many of which are in French), I have chosen to give a brief presentation of the activities of the CSTB, the activities of the FIS (Fire and safety) research programme and the activities of laboratories relating to applied fire research. I have not been able to mention all the laboratories in this field. The French section of the Combustion Institute, the CIB (Conseil International du Bâtiment), the ISo, the Sociéte Française de Thermique and other organizations and firms can provide a greater number of references to other French fire research work.

So as to limit my discussion to mathematical type modelling work and the associated experiments, I have included at the end of this text addresses and a few bibliographical references which will provide anyone interested with access to the laboratories from which they would like to obtain further information.

\section{1) The CSTB}

The CSTB's Fire safety service is now about forty years old. Like the rest of the CSTB, it is under the responsibility of the French Ministry of Housing, Equipment and Facilities. Two official test laboratories (fire reaction and fire resistance) are pilot laboratories under the control of the Ministry of the Interior. Applied research occupies a total of ten or so active people in physics of fire and safety analysis.

The history of the department's research activities can be divided into three phases: 1950 to 1975,1975 to 1980 , and 1980 to 1990 .

From 1950 to 1975: During this period, the fire safety service mainly conducted small and medium scale tests and experiments. These included a number of fire resistance research tests, fire experiments in a compartment with an internal wall lining of combustible materials, and facade fires on a two-storey configuration which is still used (LEPIR). Starting in the nineteen fifties however, calculations were 
made (with the computers of the time) for the spreading of a fire across a street. Later on, approximate calculations using simple equations, such as the A $5 \mathrm{H}$ law, were carried out as part of joint work with the CIB. Other empirical work concerned the question of smoke spreading and opacity.

From 1975 to 1980: Several factors contributed to the development of the CSTB's research activity:

- Major fires broke out which stirred up public opinion. These included the fatal fires of the saint Laurent du Pont Dance Hall (1970) and the Pailleron School (1973) which posed the question of fire safety in public buildings much more acutely.

- The instigation of national research programmes on fire in buildings under the impetus of the General Delegation for scientific and Technical Research. These programmes included the CSTB, the SNPE (National Powder and Explosives Company), Rhône-Poulenc, CERCHAR (Centre of French Coal Mine studies and Research) now called the INERIS, the CNPP (National Prevention and Protection Centre), the firm BERTIN and a dozen other laboratories including the CRCCHT in Orleans (High Temperature Combustion Chemistry Research Centre) and the LCPC in poitiers (Combustion Physics and Chemistry Research Laboratory). Research undertaken in this field has been extremely diverse and, even though all the participating laboratories have not continued their work in the direction they had initially taken, it has enabled an on-going research activity to be set up in France. The main course followed by programmes at this time was aimed at studying the behaviour of combustible materials, particularly synthetic polymers, with regards to ignition, combustion and the production of smoke or toxic compounds. It was only during later years that global modelling approaches were developed and other, more precise models appeared.

- Two contracts with the Ministry for Housing, one concerning the calculation of heat stresses in the event of a room fire and the second concerning development of a corner test, confirmed the practice of full scale fire experiments and encouraged modeling of both the fire resistance of structures and the development of room fires, particularly with respect to combustible wall materials.

- The need for studies on smoke control in buildings became clear and led to our first multi-room model (CIRFuM).

- More experimental facilities were added with the construction of an experimental base for the study of fire in one or several rooms, and high-pexformance computers and algorithms were made avaliable.

- The results of the first foreign research conducted provided a body of knowledge which was then used as a springboard. This included Swedish (LUND University) and University of California (Berkeley) research works on post-flashover modelling, American research into fire development (Harvard University and the National Bureau of Standards) as well as research conducted in England (Fire Research Station), Japan (University of Tokyo and the Building Research Institute) and Canada (National Research Council). 
- During this period, studies were conducted on experimentation and modelling of post-flashover room fires as part of joint research between the CTICM (Industrial Technical Metal Construction Centre), the FNB (National Building Federation), the SNPE (National Powders and Explosives Company) and the CSTB. The first comparisons between computer calculations and actual measurements were made on completion of several full-scale experiments at the CSTB and the SNPE. Several tests to define the characteristics of the thermal behaviour of construction materials were carried out at the FNB and CTICM. A study of the Swedish University of LUND's software by the organizations involved in this joint research encouraged further work of this type in France.

The first software simulating the development of a room fire, ISBA, was developed by the SNPE and the CSTB, based on work carried out by the University of Harvard and the NBS.

1980 to 1990: saw the growth of fire modelling and full-scale experiments some of which were conducted in parallel with the modeliing work. We will only mention a few of the most significant steps:

- First applications of the CIRFuM software simulating smoke movement in a building. CrRFuM is based on a multi-room zone model in which each room is described by a single homogeneous zone (we11-stirred reactor). The applications concerned smoke in multi-storey buildings. An experimentation and computation campaign was conducted at the CSTB (on a 7-storey building with a 28 meter stairwel1) in collaboration with the NBS, to study pressurization of the stairwell as a solution to preventing smoke spreading to the other floors.

- Research into effective computation algorithms to solve zone model equation systems (problems of stiffness, numerical precision and calculating times).

- Modelling of the CSTB's conner test and the combustion of materials partially or totally lining the vertical walls of a room naturally ventilated by a door. The model (REV) is a zone model in which the combustion of the walis is modelled semi-empirically. The model uses experimental data on the numerical combustion rate of materials and accentuates radiative transfers between the flame from the initial fire, the upper zone and the walls. A comparison was made with the experimental results, which proved encouraging.

- Numerical fire simulations in a chemistry laboratory equipped with a mechanical ventilation system in which the ventilation duct is rapidly modified during the fire. A comparison was made with the results of the corresponding full-scale experiments.

- Collaboration with the NBS's Center for Fire Research which hosted three CSTB researchers as guest-workers for several months. One of the results of this, apart from the sharing of knowledge, was the construction of a module to rapidly calculate mass per unit flow rates through the vertical openings of a room.

- Examination of flame, plume and air entrainment models 
- Application of the ISBA model (a single room, with high and low gasfilled areas) to the fire simulation of electric cables in technical premises.

- Creation of the CIFI multi-room model (a zone model with stratification) with the development of usermfriendly preparation of data files and graphic output. Incorporation of mechanical ventilation by a description of the ventilation system and incorporation of the modelling of natural ventilation circuits in multi-storey buildings.

- Designing of radiative heat transfer software (in a premises, between flames, gas and walls) with various levels of sophistication, ranging from very simple models to a complex model based on the digital integration of basic heat transfer equations.

- Development of an improved version of the FISBA software (improved zone model for a single room) and comparison with a set of experiments.

- Construction of several heat equation solving modules: monodimensional with variable properties, the reverse problem (to determine the heat flux entering a solid, from the temperature field), twodimensional transfer, etc.

- Development of the NAT software designed to calculate the thermal behaviour of structural components or equipment (walls, doors, posts, girders) in the case of a post-flashover room fire. NAT is mainly based on a zone model in which the accent is placed on solving the heat equation for various solids. For the last three years, the development and validation of NAT have been conducted in collaboration with the CTICM.

- Numerical simulation of large volumes of smoke and comparison with experimental results from the Japanese BRI. Work on this type of calculation was spurred on by the presence of $T$. Tanaka who spent a year at the CSTB.

- Application to concrete smoke problems: dimensioning of smoke vents in the case of natural ventilation and evaluation of the smoke removal system in the atrium of a paris building open to the public.

- Numerical simulations concerning the large-scale fire in the Chiado district of Lisbon in Portugal in 1988: growth of the fire in the first building which caught alight, spreading of the fire through the streets by radiative heat transfer, heat conduction in stone waIls.

- Forecasting and full-scale evaluation of the behaviour of mobile shelters in the case of a brush fire (in collaboration with the (NPP).

- Studies of industrial hazards. For example, calculation of the thermal stresses of a hydrocarbon storage fire on a civil engineering structure or neighbouring facilities. 
- Other experimental work, not presented here, concerns evaluation of the real life behaviour of building products, equipment and furniture. Toxicity of the combustion products is being evaluated on an animal model in collaboration with university laboratories.

These activities were financed by the CSTB's research fund (under the responsibility of the Housing Ministry), individual contracts with the above Ministry and the Civil Safety Department of the Ministry of the Interior and by other contracts with several ministries, public organizations and private companies (Ministry of the Defense, Atomic Energy Commission, French rallways, the electricity and gas utilities, etc.)

\section{Current trends:}

- The Ministry of the Interior has been encouraging us over the last few years to define a method for regulating the use of some of our software, in two respects: calculation of fire resistance based on the simulation of real fires and definition of smoke removal requirements in public buildings (conference rooms, corridors, atriums, etc). Widespread use of computation software is envisaged during the next few years as part of current European harmonization work.

- The evaluation of fire safety in the real world based on eventoriented models and probabilistic networks has been stepped up since 1985. A presentation of the $\mathrm{CSTB}^{*} \mathrm{~s}$ model and software is being given during this Symposium by my colleagues B. Hognon and M. Zini.

- In the work being carried out at the CSTB, the emphasis is on practical applications. Some examples are development of the use of models of varying complexity for engineering works and the project to pool current modelling possibilities in order to define new European fire tests.

Several of the subjects presented above correspond to different stages in the FIS research programme which we are now going to outline.

\section{2) The FIS Group}

In 1980, a project to organize French fire safety research on a national scale was set up by representatives of the university, the CNRS (National Scientific Research Centre), industry and the CSTB. Prior to 1983, a few Iaboratories began working together on upstream research relating to accidental fires; they were later joined by BERTTN and the CSTB to develop room fire simulation software whose model would be based on the resuits of basic research laboratories. Management of the programme was funded by the Ministry responsible for Research up unti1 1987. Detailed information on the contribution of basic research is included in the annual reports mentioned in the bibliography. We will limit ourselves here to a brief summary of the research work carried out: 
- modeling and experimentation to determine the rate at which combustible materials deteriorate (PMMA and wood) - a thermal and kinetic approach to pyrolysis.

- study of plumes of smoke and flames. Modelling of flames and air entrainment.

- Eine measurement of the characteristics of a turbulent diffusion flame;

- modelling of the heat flux radiated from a diffusion flame;

- study of wall injection combustion;

- study of the formation of soot in a diffusion flame;

- experimental study of the optical properties of combustion products.

BERTIN and the CSTB collaborated up until 1987 on the development of software for the simulation of room fires, based on zone models. The main aspects of this collaboration concerned the following:

- organization of the model and software;

- the algorithm used: numerical equation solving methods;

- solving the heat diffusion equation;

- radiative and convective transfers;

- measurement of gas flow rates through vertical openings;

- validation by comparison with the results of full-scale experiments.

At the end of the FIS programme, the CSTB had produced the first version of the FISBA software (advanced single room zone model) and the CIFI software (multi-room zone model). A summary of this phase, for all of the laboratories, is given in the issue of the "Revue generale de thermique" mentioned in the bibliography.

A new FIS programme was begun in 1988, directed towards the applied research target of disposing, in 1993, of software to simulate the smoke movement in a building which could be more widely used to deal with practical problems and help define regulatory requirements. The cSTB is the main partner of the "Direction de la sécurite Civile" (Ministry of the Interior) in this programme. Several basic studies concern smoke:

- modeling of the growth of aerosols;

- development of the soot and aerosols concentration in a flow subjected to an imposed heat flux;

- examination of how liquid and solid particles are formed;

- study of the stability of the stratification of smoke moving through a corridor; 
- modelling of advancement of the smoke front through a corridor.

These studies are being carried out by the university and CNRS laboratories participating in the programme. From an applied research point of view, the work conducted concerns the following:

- smoke control of atriums using CIFI (see paper given by X. Bodart et al in this symposium);

- smoke control in a room/corridor configuration. Experimental study of a mock-up, simulation by field and zone models (see paper by $M$. Curtat et al, during this symposium);

- mechanical smoke control of premises such as shops (zone and field models);

- experiments and calculations in a large room with a mobile ceiling.

At the end of the current phase of the FIS programme, a new project is to be developed for 1993, aimed at associating mathematical modelling of fire physics and probabilistic safety analysis.

3) Activities of laboratories and research centres in the field of fire physics (non-exhaustive list)

\section{1 - CEA (Atomic Energy Commission)}

The CEA carries out a large number of safety studies concerning industrial risks including fire which, in a nuclear environment, can add the further danger of radioactive contamination to the other fire dangers present.

In nuclear safety, the role played by the containment (which includes the associated ventilation) is primordial in dealing with the problems Iinked to radioactivity. A fire arising in a compartment can lead to the fallure of the containment and to the spreading of contamination in the surroundings of the building. So, one has to: dimension the containment and its ventilation network in order to contain the fire, contain the products within the containment by filter systems, reduce the consequences of the fire by using passive and active means of extinction, determine the instructions to be followed in case of fire, determine the rules that must be applied after the incident. The studies carried out are aimed in particular at making computation and simulation tools available to the people concerned. In this context, for more than ten years now, the CEA has been developing fire physics software which has been compared with the results of full scale experiments (carried out in compartments which vary in size from 316 liters to $3600 \mathrm{cu} . \mathrm{m}$.) also conducted to evaluate the technology of safety equipment. The results of this research concern several specific products - pyrophoric metals (sodium, lithium and magnesium) and non-metallic materials such as kerosene, oil and bitumen. Several types of software have been developed, whose characteristics are related to the different types of fire:

- The pYRos 2 code concerns metal fires. This code contains several software packages which are interconnected: PYROS 1 (pool fires), Pulsar (spray fires), Feumix (mixed fires), Sorbet (water desorption 
and heat transfer through concrete), Ressort (sodium - concrete reaction), Aerosol B2 (aerosol behaviour), Icainna (atmospheric dispersion), Commod (wall conduction), cheminee (transients in pipes), Liquinet (ventilation network) and Ventilation (vent holes and valves).

- Three other software packages concern carbon compound fires: FLAMME 1 (a single fire), FLAMME II (several fires in the same building) and FLAMME III which is currently being developed and is aimed at describing plumes of smoke outside a building and the discharge of toxic or corrosive products into the environment.

The three FLAMME packages describe the ventilation of rooms either using the Bernouilli law, or the "Cheminee" software mentioned above, or else a ventilation network model in the unsteady state.

A new direction in the CEA's fire safety research is the development of a forest fire model whose validation will be based on accidents which have occurred during the last few years in the south of France.

\section{2. - Activities of BERTIN \& Co.}

This engineering firm is a service company for the following aspects of fire safety: assistance to manufacturers in developing special software for confined and unconfined fires, modeling of physical phenomena (flames resulting from pressurized waste and heat radiation, for example), deterministic fire propagation studies in a set of premises, probabilistic analyses and the development of extinguishing systems. Requests for this type of service mainly come from the nuclear industry and the combustible gas and petroleum sectors. The strategical importance of this research for industrial safety also concerns the prevention of major accidents, environmentaltype restrictions and the study of fire-related dangers. Several software programs have thus been developed and evaluated by comparison with full scale experiments.

- VESTA-PLUS is a software program to simulate the development of room fires, based on a zone model. It has been compared with the results of fire experiments in bedrooms and submarine compartments. The software has been applied to fires in submarines and nuclear power plants, based on scenarios resulting from in-situ analyses. The possibility of a fire spreading to a neighbouring room has been evaluated together with the effects of fire on electricity cupboards.

- SICIF is based on a multi-room zone model. It has been applied to an examination of the possible consequences of a hot gas pipe bursting in a nuclear power plant in order to predict the thermal behaviour of sensitive equipment, depending on where the pipe bursts. More generally speaking, this program enables the circulation of hot gas and smoke to be simulated in industrial premises.

- KARATE calculates the field of heat radiation around a large gas flame in the presence of wind. The model includes turbulent flows with chemical reactions in three-dimensional geometry and predicts 
the soot concentration. A radiation measurement data base has been set up based on 80 full-scale flaring trials. This software program has been evaluated on large-scale gas flares in cross-wind conditions and is applied to the calculation of radiative fluxes from large gas flames.

Bertin \& Co. is also interested in modeling problems related to explosions caused by combustion - gas or clouds of oil droplets, for example - in order to simulate the effects of various explosion scenarios. Another recent trend concerns the production of userfitiendly software to be used in safety studies. Modeling work is in progress on the production and destruction of soot in flames.

\section{3 - EDF, (the French electricity utility)}

The following is taken from the journal "Epure", published by Electricite de Erance, Department of Studies and Research (n ${ }^{\circ} 19$, July 1.988):

"The use of complex synthetic products and the limitation of the surface area available for buildings increases the potential risk of fire. For EDF, the fire-safety of its premises and power plants is therefore an increasingly important factor. In the same way as for residential buildings, construction materials are systematically tested and governed by strict standards.

Furthermore, the vigilance of the operating teams has enabled the incident occurrence rate to be kept to a very low level. The number of fires per Megawat in the service recorded every year has thus been divided by a factor of five over the last thirty years, and the damage caused is nearly always slight.

Several fires have however shown that independent qualification of materials is not enough and that the architecture and ventilation of the buildings has a significant effect on the seriousness of the fire.

The global description provided by numerical modelling thus constitutes an effective complement to the standardized tests. The MAGIC computation code is developed and employed by Electricite de France to back up the design of nuclear power plants with parametric studies, and to evaluate the effects of fire prevention and firefighting means.

Experiments are conducted in parallel with these computations to determine the necessary data, test the validity of the assumptions used and back up the formulae employed. This combination of numerical and experimental resources has made combustion one of the most fruitful current research areas."

The MAGIC software is based on a multi-room zone model which has been developed for several years by EDF. The model can consider several fires and both natural and mechanical ventilation. A preprocessor and a post-processor use graphic software to facilitate data input, visualization of premises and representation of the results. An extension of the scope of MAGIC is underway - non-rectangular convex and sloping roofed rooms, rooms cluttered with objects, spread of fire 
through ventilation ducts, extinction of the fire, other studies are being continued to improve modelling of the behaviour of combustible materials, particularly electric cable insulation.

3.4. - INERIS (Nationa1 Institute for the Industrial Environment and Risks)

INERIS is a recent institute created at the beginning of 1991 whose mission is directed towards the study of industrial dangers and risks, particularly to the environment and population. This institute is an offshoot of CERCHAR (the French coal mining utility's former study and research centre) whose vocation was to conduct research into mining safety, particularly with regard to explosions and fires. INERIS is attached to the Ministry of the Environment. Its fire safety activity is still mainly experimental and aimed at contributing to knowledge of the physico-chemical aspects of fire development and their consequences. The main fields explored are as follows:

- spontaneous heating and explosion of combustible pulverulent materials;

- reaction to fire (in a broad sense - combustion, production of pollutants) and toxicity of smoke and fumes for various gaseous, liquid and solid chemical compounds.

Its activities can be presented in the following way:

- Management of risks relating to the handling, storage and use of pulverulent materials

The materials concerned are wood, coal, agro-food products, plastics, metals and chemicals. The industrial processes which present these risks are also extremely diverse - slios, filters, grinders, handling equipment, driers, heating apparatus, etc. - as well as their causes of combustion - open fires, electric or mechanical sparks, static electricity, welding, spontaneous heating. The experimental studies are aimed at understanding the phenomena involved and evaluating the dangers. The use of powdered coal (in cement works, iron and steel works, boilers, etc.) poses new problems of fire safety and explosion to which research is being devoted.

\section{- Management of fire risks in the industrial environment}

Defining the inflammability and combustibility properties of chemicals, materials and equipment is one aspect of these activities.

Fire development is studied on a full scale in the INERIS' "fite gallery". Tests are conducted under realistic conditions, on $100 \mathrm{~kg}$ to $1000 \mathrm{~kg}$ of products or on complete facilities. In particular, these tests enable the toxic impact of smoke to be determined. In prevention programes to replace pyralene transformers with other types of equipment, CERCHAR conducted a full-scale analysis of liquid dielectric transformers and air-cooled transformers in a fire situation. 
In the field of chemistry, experiments are being carried out on fires relating to agro-phamaceutical (phytosanitary) products. Within the framework of a special expert appraisal for the Ministry of the Environment, CERCHAR reproduced the Nantes fire (burning of a fertilizer storehouse with the formation of a "suspect cloud" which resulted in the evacuation of more than 30000 people).

\section{- Fires and toxicity of smoke and fumes}

More and more synthetic materials are being used in mining to increase pay-back and working conditions. The introduction of these new products can modify the nature of the fire risk in mining. The INERIS is working on determining the characteristics of fire propagation and the emanation of toxic smoke and fumes in order to select the safest materials.

Here is one last example in which all the aspects of fire safety are dealt with in a fulI scale test: the CERCHAR, in collaboration with Transmanche-Link and Eurotunnel, has conducted and is continuing to conduct original studies and experiments concerning the fire safety of shuttles designed to transport coaches and cars through the tunnel under the English Channel.

\section{- Research trends}

The INERIS's mission will direct fire safety research more towards an evaluation of its consequences on the population and the environment (accidental pollution). Fire reaction activities, both in the laboratory and on a full scale, will be stepped up.

\section{5. - The CNPP (National Prevention and Protection Centre)}

The CNPP conducts its activities on its Vernon site, between Paris and Rouen. Its mission is to solve problems posed by industrial firms. It collaborates with the main government offices in carrying out a certain number of tests. Its 240 hectare grounds are used to conduct training courses for a wide range of people, from basic firemen to safety engineers.

- Nearly one hundred $200 \mathrm{~m}^{2}$ and $400 \mathrm{~m}^{2}$ hydrocarbon fires are lit every year, to train personnel as part of its GESIP (Petroleum Fire safety Study Group) training activities. These fires are also used to evaluate emulsifiers. Over the last few years, the emphasis has been on more fundamental studies concerning fires on layers of liquid combustibles such as petrol, gas-oil, heptane, alcohol and acetone. Measurements are taken of the mass burning rate, the flame temperature, the radiated heat fluxes and the height of the smoke plumes. The dimension of the fires ranges from $0.2 \mathrm{~m}^{2}$ to $7 \mathrm{~m}^{2}$, sometimes $30 \mathrm{~m}^{2}$. Large fires of 200 and $400 \mathrm{~m}^{2}$ only concern a few products for the moment. The $\mathrm{CO}, \mathrm{CO}_{2}$, soot and polycyclic aromatic hydrocarbon content of smoke. has been measured under special circumstances, on samples taken from a plane flying through the plume of smoke above the test site.

- With EDF, a large number of tests have been carried out on the propagation of fire on layers of vertical and horizontal cables. The 
phenomena studied include the influence of supports and fixations, the spacing of the cables, the density of the layers, the ceiling effects (a hot layer under a ceiling or another material or under another horizontal layer).

The horizontal layer tests were carried out in a $70 \mathrm{cu} . \mathrm{m}$. building. During the largest test, 6 tons of cables were burnt.

Tests are carried out on power transformers in order to draw up specifications. Half-scale tests are being prepared to study oil fires and the best way of extinguishing them.

- Manufacturers often turn to the CNPP to help solve their raw material or finished product storage problems. The entire chain is then studied - combustion, detection, propagation and extinction. Tests are carried out on storage reconstructions often involving 10 to 15 pallets, in order to reconstruct all the elements which could encourage propagation - draught effects, surface propagation, opening of packaging, collapse of pallets, etc. For expensive materials, some of the pallets used are dumies.

- Sprinklers are tested in a room with a floor surface area of $50 \mathrm{~m}^{2}$, equipped with a mobile celling whose height can vary from 3 to 7 meters. The room is also equipped with an adjustable smoke control system.

- In collaboration with the CSTB and the University of Poitiers, Thermal studies Laboratory (L.E.T.), and as part of the EIS programme, an experimental study is being conducted on the stratification of smoke according to the strength of the fire and the smoke removal rate. This study will enable computation models to be validated.

- Special studies have also been carried out on various subjects such as fire detection and development in student bedrooms, and the extinction of fires involving rubber tyres, archives and even cognac storage vats.

- The first few minutes of the development of a voluntary fire are quite different from those of a natural fire since the person lighting the fire modifies the surroundings. A voluntary fire can be recognized from certain. clues of an investigatory type. Charred fragments taken from certain critical points, identified as the primary seat of fire have also been analyzed in order to look for inflammable liquids. This requires a data bank on products released by the combustion of various commonly used materials and inflammable Iiquids.

- Studies conducted by the CNPP in vernon are directed towards practical applications rather than basic research. However, fullscale test facilities are used both by industrial firms and those whose vocation is directed more towards the theoretical knowledge of fire phenomena. 
3.6. - C.T.I.C.M. (Centre Technique Industriel de la Construction Metallique)

- Research on the fire behaviour of composite beams (concrete + steel) and composite slabs with profijed steel sheet.

This reseearch sponsored by EEC involved also TNO (The Netherlands) and ARBED (Luxembourg).

CTICM is mainly in charge with composite beams. This reserach is shared into 3 phases:

- Mathematical modelling of the mechanical behaviour of composite beams (statically determinated or undeterminated) taking into account the effort-slipping relationships of shear connectors (between concrete slab and steel profile) and creep effects.

Fire tests on small scale specimens (push out test) and on full scale specimens (loaded beams).

- Simple models to be introduced Eurocode 4 - part 10 .

A first stage on statically determinated elements is nearly finished.

The second stage concerning statically undeterminated elements will be finalized at the end of 1992 .

- Modelling of fire behaviour of steel frames ( 2 and 3 D) with finite elements, taking into account post bukling behaviour

- Research on the optimal way to characterize the coating material of steel. structures in order to determine thermal conductivity versus temperature of the material and to avoid too many fire tests

- Collaboration for research on :

- Natural fire (with CSTB)

- Expert systems (with Federation Nationale du Batiment)

\section{7. - LCPC (Laboratory of Combustion Physics and Chemistry, University of Poitiers)}

This laboratory conducts basic and applied research in the field of combustion. Its activities in the field of accidental fire are as follows:

- Turbulent reactive flows. Pool fires (aerodynamics, temperature fields, rate of pyrolysis, radiative heat fluxes) and wall fires.

- Thermal radiation and combustion - the radiative properties of flames (gas and particles), calculation of radiative fluxes, pyrolysis and combustion.

On an experimental level, the LCPC uses the 2D Doppler Laser anemometer technique for all types of flames and various instrumented 
combustion configurations including vertical burners to simulate interactions between walls. From a modelling point of view, the most advanced work concerns radiation models with computation of radiative characteristics and elliptical and hyperbolic combustion models . Applied fire safety studies include the following:

- A study being conducted to analyze smoke transport mechanisms in a tunnel under various initial and boundary conditions. An experimental model and a parametric analysis are being used to build a simple model.

- Development of a model to simulate radiation from the flame of a pool fire with a cross-wind based on full-scale experiments.

- Continuation of experimentation and modeling of the interaction involved in wall fires (wall/wall and wall/floor). Extension of this type of work to modelling of a corner test.

- Modelling of wall fires, sometimes in the presence of wind, in order to build a fire model applied to the environment.

- Combustion in microgravity conditions (safety of space vehicles).

- Experimentation and modelling of the flow of smoke currents under the effect of thermal irradiance (as part of the FIs programme).

\section{8. - CRCCHT (Combustion and High Temperature Chemistry Research Centre, Orleans)}

The CRCCH'T conducts research into the following main aspects of the physical chemistry of combustion with regards to fire - the chemical kinetics of combustion in the gaseous phase, combustion and turbulence, chemical explosions and reactions in shock waves and detonation, oxidation pyrolysis and combustion, surface reactions of solids (thermal degradation, heterogeneous reactions, pyrolysis and gasification), basic chemical reactions in the atmosphere.

Work more directly related to fire safety includes the following:

- experiments and modelifing work (modeliing in collaboration with the University of Paris VI's heat exchange laboratory) on the rate of deterioration of combustible materials. Solving the heat equation is coupled with a local equation of pyrolysis kinetics. The parameters of the kinetics law have been determined by thermogranimetric analysis for several materials (study conducted as part of the FIs programe).

- definition and production of a calorimeter adapted to the properties of electric cable insulating materials. The calorimeter chosen and made is used to directly measure the calorific power transported by convection and then radiated. The calorimeter will be equipped with a system to measure the amount of oxygen consumed in order to determine the effect of the presence of halogen atoms (for example, chlorine in PVC) on the heat released by combustion. 
A new study has been undertaken to calculate the rate of pyrolysis and combustion of various compounds subjected to external irradiance easily inflammale liquids and liquids and solids presenting high risks of pollution (pesticides and herbicides, for example).

\section{9. - Aerology Laboratory (University of Toulouse)}

This laboratory specializes in the experimental and theoretical study of aerosols. After conducting granulometric measurements of various types of aerosols capable of simulating those produced by fire, as part of the EIS programme, the Aerology Laboratory began a study concerning modelling of the absorption and diffusion of light through a layer of smoke. A large part of the study concerns modelling of changes in the size of the water particles which condense on the particle initially produced by combustion and can lead to droplets which can then modify the optical characteristics of the medium and hinder visibility. Input data on the overall composition of the atmosphere, its temperature and the speed of air flows in realistic fire situations are supplied by the CSTB's CIFI multi-room software. The final aim of the study is to develop an advanced computation module for the optical properties of rooms filled with smoke from a fire.

\subsection{0. - LET (Thermal Studies Laboratory, Poitiers)}

Generally speaking, the activities of the Thermal studies Laboratory at the University of poitiers are directed towards the study of. flows in the presence of heat and mass transfers. Over the last few years, part of the research work in this field has been devoted to the problem of smoke in rooms. The work has been carried out as part of the FIS programme. The laboratory is particularly interested in flows resulting from a fire located in an inhabited room leading onto a corridor open to the outside, with or without a smoke extraction system.

\section{- Facilities}

The laboratory has a computation code based on the sIMEc field model, to solve local equations concerning the conservation of mass, momentum and energy for $3 \mathrm{D}$ turbulent flows. This code is based on an iterative numerical method of the finite volume type. The laboratory is also equipped with large-scale experimental facilities, a tomographical bench for the visualization of flows, laser velocimetry chains for the local measurement of velocity and temperature acquisition systems. These experimental facilities have been implemented on a $1 / 3$ scale mock-up of the room/corridor configuration.

- Validation of the computation code: the computation code adapted to the $3 D$ configuration studied has enabled the main characteristics of flows to be determined: scale factors, influence of parameters, influence of mechanical extraction. At the same time, the velocity and temperature were measured on an experimental set-up (1/3 scale) in order to validate the numerical results obtained. 
- Currently, studies more specifically concern problems relating to smoke exhaust in large rooms: determination of the effectiveness of a mechanical extractor, study of the "punching" effect i.e. the parasitic aspiration of fresh air caused by extraction, optimization of extraction conditions (flow rate, position of extractor, etc) with regards to air quality criteria.

prospects: In the near future (1991-1992), studies relating to the problem of smoke should be continued in two directions:

- comparison of the results of the sIMEc computation code with the experimental results obtained on a full-scale configuration at the CNPP;

- a theoretical and numerical study of the behaviour of hot plumes of smoke in rooms with very high ceilings. 


\section{CSTB}

Mr M. CURTAT, CSTB,

84 avenue Jean Jaurès, Champs-sur-Marne BP 02 - 77421 Marne la Vallée Cedex 2, France

- BODART, X.E., CURTAT, M.R., HOGNON, B.H. and ROUYER, J.L., NumeriCaI Simulation of Thermodynamical Characteristics Evolution in an Air Handling System Equipped Laboratory in case of Accidental Fire, CSNI Report No 83, LA-9911C, vol 1, Los Alamos, New Mexico, April 25-28, 1983

- CURTAT, M.R., Simulation du feu: I'inflammation, Face au Risque, May 1985

- KLOTE, J.H., and BODART, X.E., VaIidation of Network Models Smoke Control Analysis, ASHRAE Meeting, Hawai, June 1985

- BODART, X.E. and JONES, W.W., Buoyancy Driven Flow as the Forcing Function of Smoke Transport Equations, ASME meeting, Denver, August 1985

- CURTAT, M.R. and BODART, X.E., Simple and not so Simple Models of Fire Growth in a Compartment, $1^{\text {st }}$ symposium of IAFSS, October 1985

- CURTAT, M.R., "Modèle Physique de la Prévision de la Résistance au Feu des Structures en cas d'Incendie Naturel", CSTB report, November 1985

- CURTAT, M.R., "Etude des Débits de Pyrolyse d’objets Réels", CSTB report, November 1986

- CURTAT, M.R., La modelisation Physique du Eeu, CSTB Magazine, February 1987

- CURTAT, M.R., Ordinateurs, Modeles et Incendies, Face au Risque, March 1987

- NICOLIN, J.P., and CURTAT, M.R., "Comportement au Feu d'Eléments Métalliques Protéges", CSTB report, September 1987

- BODART, X.E., Feux Industriels et Risque de Contamination, CSTB Magazine, February 1988

- BODART, X.E., and CURTAT M.R., Prediction of Entrained Mass Elows through Vertical openings in a Multiroom Fire Model, $2^{\text {nd }}$ Symposium of IAFSS, Tokyo, June 1988

\section{EIS Programme}

- Annual Reports are available (ask M. CURTAT, CSTB)

- Special issue of "Revue Generale Thermique", $n^{\circ} 315-316$, Apri1 1988 
Mr J.C. MALET, C.E.A., CEN de Cadarache, IPSN, Section d'Etudes des Feux, 13108 Saint Paul lez Durance Cedex, France

- ROY, D., MALET, J.C., BEZIAUX, J., CASSELMAN, C, , CHARPENEL, J., DUVERGER, G., FERMANDJIAN, J., VIARD, M.F., Sodium Fires computation in France, Fast Reactor Safety Technology (Proc. Int. Mtg Seatle, 1979), Vol. 3., American Nuclear Society, Hinsdale, IL (1979) 12011211

- MALET, J.C., DUVERGER, G., Calculating the conseguences of a kerosene pool fire: The FLAMME computer code, Interaction of Fire and Explosion with Ventilation systems in Nuclear Facilities (Proc. CSNI Spec. Mtg Los Alamos, 1983), Vol. 1, Los Alamos Nationa1 Laboratory, Los Alamos, NM (1983) 169-183

- MALET, J.C., DUVERGER, G., Magnesium fires combustion and extinction, Liquid Metal Engineering and Technology (Proc. 4 Int. Conf. Avignon, 1988), Vol. 1, Société française d'energie nucleaire, Paris (1988) 207

- MALET, J.C., "Ignition and combustion of sodium fire consequences Extinguishment and prevention", Safety Problems Related to Sodium Handling in LMFBR and Large Test Facilities, ISPRA Courses on Nuclear Engineering and Technology (KOTTOWSKI, M.H., Ed.) (Nov. 1980) $143-176$

- MALET, J.C., DUVERGER, G., GASTETGER, R., JANBERG, K., SOIVent pooI fire testing. Interaction of Fire and Explosion with Ventilation Systems in Nuclear Facilities (Proc. CSNI Spec. Mtg. Los Alamos, 1983), Vol. 2, Los Alamos National Laboratory, Los Alamos, NM (1983) $391-405$.

- R. RZEKIECKI, J.C. MALET, Model for simple or multiple fires in a ventilated and system code development. SMIRT 10 Post conference $n^{\circ}$ 6. Fire Safety of Nuclear Power Plants. ANAHEIM 21-22 August 1989

- SOPHY, Y.M., LOUBRIAT, M., BENTZ, A., GEROSA, A., FRESLON, H., and PIATTI, U., "Esmeralda project for studying extensive sodium fires" (Proc. LMFBR Top. Mtg Lyon, 1982), Vol. 3, Société française d'énergie nucléaire, Paris (1982) 171-183

\section{Societe BERTTN et Cie}

Mr D. GROUSET, BERTIN, ZI 40220 Tarnos, Francé

- GROUSET, D., REBUFFAT, D., VACHON, M., and BRAUNS, P., Application of Fire Models for Risk Analysis in French Nuclear Power Plants, Proceedings of an International Symposium "International Atomic Energy Agency", Vienna, 27 February - 3 March 1989

- GROUSET, D., REBUEFAT, D. and VACHON, M., "Fire and Flare Modelling in Safety Analysis", third International Conference on Topside Design and Construction, London, 6th/7th March 1989 
- Annual FIS reports 1983 to 1987

\section{EDF (Electricite de France)}

Mrs AUBRY, EDF DER, Département TTA,

6 quai Watier, 78401 Chatou Cedex. France

- RONGERE, E.X., "Fighting Fire with MAGIC", EDF pub. Epure, $\mathrm{n}^{\circ} 19$, July 1.988

INERIS (Institut National de 1'Environnement Industriel et des Risques)

Mr C, CWIKIINSKI, INERIS, Groupe Incendies,

Parc Technologique Alata, BP $n^{\circ} 2,60550$ Verneuil en Halatte, France

- CWIKLINSKI, C., L'essai en grand : une Approche Préventive et Prévisionnelle pour l'Incende en Milieu Industriel, Revue Générale de sécurité no 97 , october 1990

- BURGHART, $\mathrm{P}$, and LÖDEL, R., Les incendies de sechoirs de Tournesol, Revue Générale de Securite $n^{\circ} 95$, July 1990

- CHAUVTN, R., LÖDEL, R., NOMINE, M., and PREGERMAIN, S., "Safety in stocage and Transport of Pulverized coal", First European Conference on Dry Fine Coal", First European Conference on Dry Fine Coal, Hanogate, June 1987

- CWIKLINSKI, C., LÖDEL, R., FROGER, C., and BRIGOURD, J., "Stratégie de Sécurité Incendie", $23^{\text {th }}$ International conference on Safety in Mines, Washington DC, September 1989

- LEROY, E., and SANDOZ, F., "Evolution des Systemes d'Isolation dans Les Transformateurs de Distribution en Relation avec l'Amelioration du Comportement au Feu", CIRED meeting, Brighton, 1985

\section{CNPP (Centre National de Prevention et de Protection)}

MI Y. LE BOTLAN, CNPP,

Route de la Chapelle-Réanvilie, BP 2265, 27950 st Marcel, France

\section{CTICM (Centre technique Industriel de la Construction Métallique)}

Mr J. KRUPPA, CTTCM,

Domaine de Saint Paul, BP n. ${ }^{\circ}$, 78470 st Rémy les Chevreuse, France

LCPC (Laboratoire de Chimie Physique de la Combustion)

Mr P. JOULATN, LCPC,

Domaine du Deffend, 86800 Mignaloux-Beauvoir, France 
- ANNARUMMA, M., MOST, J.M., JOULAIN, P., Experimental Study of a Vertical Burning Wall and its interaction with a Pool Fire Close to it, Proceedings of the $g^{\text {th }}$ International Heat Transfer conference, Vol. 4, P 167, Jerusalem, August 1990

- ANNARUMMA, M., MOST, J.M., and JoUlAin, P., Velocity and Temperature Measurements in a Bidimensionnal Pool Fire. Influence of a Vertical Wall close to it, $12^{\text {th }}$ International Colloquium on Dynamics of Explosions and Reactive Systems, Ann Arbor, July 1989 (pub. AIAA)

- MOST, J.M., and JOULAIN, P., Modélisation Numérique et Validation Expérimentale de Elammes de Diffusion Turbulentes, Paper $n^{\circ} 22$, Vol. I, Proceedings Eurotherm Seminar $n^{\circ} 14$, Heat Transfer and Major Technological Hazards, Louvain, May 1990

- BOUHAFID, A., VANTELON, J.P.,, FERNANDEZ PELLO, A.C., and JOULAIN, P., On the Flame structure at the base of a Pool Fire, $22^{\text {nd }}$ Symposium (International) on Combustion, The Combustion Institute, $p$ 1291,1989

- MOST, J.M., BELLIN, B., and JOULAIN, P., Interaction between two Burning Vertical Wa11s, $2^{\text {nd }}$ International Symposium of IAFSS, 2285 , 1989

- BOUHAFID, A., SOUIL, J.M., VANTELON, J.P., and JOULAIN, P., Transferts radiatifs de Flamme a Base Horizontale. Cas d'une Flamme de Kérosène, Revue Générale de Thermique, $\mathrm{n}^{\circ} 316, \mathrm{p} 170,1988$

- MOST, J.M., KIM JIN KON, BELLIN, P., and JOULAIN, P., Etude Expérimentale et Théorique d'un Feu de Paroi Verticale et de la Zone de Propagation, Ibid p 228, 1988

- Annual FIS reports 1983 to 1990

CRCCHT (Centre de Recherches sur la Chimie de la Combustion et des Hautes Temperatures)

Mr H. MELLOTTEE, CRCCHT,

1C, Avenue de la Recherche Scientifique, 45071 orleans Cedex 2, France

- Annual FIS reports 1984 to 1986

- VOVELLE, C., AKRICH, R., DELFAU, J.L., and GRESILLAUD, S., InfIuence of the Thickness on the Thermal Degradation of PMMA, Proceedings of the $1^{\text {st }}$ Symposium of IAFSS, 1986

- VOVELLE, C., DELFAU, J.L., and REVILLON, M., Détermination du Débit de Pyrolyse de Materiaux solides Soumis a un Flux de Chaleur Radiatif, Revue Générale de Thermique, $\mathrm{n}^{\circ} 315, \mathrm{P} 187,1988$

- VOVELLE, C., BASTIN, E., DELFAU, J.L., AKRICH, R., and REVILLON, M., "Flame Structure Studies in Relation to Soot Precursors Formation", $3^{\text {rd }}$ International seminar on Elame Structure, Alma Ata (URSS), September 1989 


\section{Laboratoire d'Aérologie de 1'Universite de Toulouse}

Mr A. LOPEZ, Laboratoire d'Aerologie, Universite Paul Sabatier, 118 route de Narbonne, 31062 Toulouse Cedex, France

\section{LET (Laboratoire d'Etudes Thermiques)}

Mr D. BLAY, LET,

40, Avenue du Recteur Pineau, 86022 Poitiers Cedex, France

- Annual FIS reports 1984 to 1990

- BLAY, D.E., and TUHAULT, J.L., "Experimental study of Convective Turbulent Flow created by a Heat source in an Open Cavity", $9^{\text {th }}$ International. Conference on Heat Transfer, Jerusalem, August 1990 